\title{
Virological, serological and histopathological evaluation of fish strain susceptibility to experimental infection with salmonid alphavirus
}

\author{
M. F. McLoughlin ${ }^{1, *}$, D. A. Graham ${ }^{2}$, A. Norris ${ }^{3}$, D. Matthews ${ }^{4}$, L. Foyle ${ }^{5}$, \\ H. M. Rowley ${ }^{2}$, H. Jewhurst ${ }^{6}$, J. MacPhee ${ }^{7}$, D. Todd $^{2}$ \\ ${ }^{1}$ Aquatic Veterinary Services, 35 Cherryvalley Park, Belfast BT5 6PN, Northern Ireland \\ ${ }^{2}$ Veterinary Sciences Division, Department of Agriculture and Rural Development for Northern Ireland, Stoney Road, \\ Belfast BT4 3SD, Northern Ireland \\ ${ }^{3}$ Marine Harvest Ireland Ltd., Kindrum, Letterkenny, Co Donegal, Ireland \\ ${ }^{4}$ Biometrics Branch, Department of Agriculture and Rural Development for Northern Ireland, New Forge Lane, Belfast BT9 5PX, \\ Northern Ireland \\ ${ }^{5}$ Department of Veterinary Pathology, Faculty of Veterinary Medicine, University College Dublin 4, Dublin, Ireland \\ ${ }^{6}$ Queen's University of Belfast, Stoney Road, Belfast BT4 3SD, Northern Ireland \\ ${ }^{7}$ Marine Harvest Scotland Ltd., Trails Unit, Lochailort PH38 4LZ, Inverness-shire, UK
}

\begin{abstract}
Pancreas disease (PD) of farmed Atlantic salmon Salmo salar L., which is caused by an alphavirus known as salmon pancreas disease virus (SPDV), can have serious economic consequences. An epidemiological survey carried out in Ireland in 2003 indicated that within individual farms there were significant differences in the susceptibility of different strains of farmed Atlantic salmon to infection with SPDV, as measured by levels of clinical disease and mortality. The aim of this preliminary study was to investigate this field observation by comparing lesion development, viraemia and serological responses of 3 commercial strains of Atlantic salmon (A, B and C) experimentally infected with SPDV. Highly significant differences in the severity of lesions in the pancreas at Day 21 post-infection (pi) were detected $(p<0.01)$, with Group B being more severely affected. There were also significant differences in the prevalence and severity of lesions in heart and skeletal muscle at Day 21 and 35 pi respectively, with Group B results again significantly higher than those from both Groups A and C ( $p<0.05)$. There was no overlap between viraemia and the presence of specific SPDV antibody. Some fish in all groups had no viraemia, lesions or evidence of seroconversion. There were no significant differences seen between the challenged groups in relation to the percentage of viraemic fish at each time point. Viral loads were not determined. Differences between the number of antibody-positive fish in each challenge group were found at Days 28 and $35 \mathrm{pi}(\mathrm{p}<$ $0.1)$. Highly significant differences $(p<0.01)$ in the geometric mean titres of seropositive fish were detected at Day 28. These results, obtained using a challenge model, confirm that there are strain differences in the susceptibility to experimental SPDV infection in commercial farmed Atlantic salmon.
\end{abstract}

KEY WORDS: Salmon Pancreas Disease Virus - SPDV · Atlantic salmon · Disease susceptibility • Experimental challenge

\section{INTRODUCTION}

Pancreas disease (PD) in farmed Atlantic salmon Salmo salar L. was first recognised in Scotland in 1976 (Munro et al. 1984, McVicar 1987, 1990, Ferguson et al. 1986a, 1986b, Rodger et al. 1994). Rodger et al. (1991) and Murphy et al. (1992) published the first descriptions of PD in Ireland. It has also been described in Norway by Poppe et al. (1989) and in North America by Kent \& Elston (1987). Salmon pancreas disease virus 
(SPDV), the aetiological agent of PD, was isolated in 1993 (Nelson et al. 1995) and was subsequently classified as a salmonid alphavirus (SAV) (Weston et al. 1999, 2002).

National surveys in Ireland from 1989 to 1994 indicated that mortality owing to PD could be up to $48 \%$, with $94 \%$ of Irish marine sites affected, and that PD was the major cause of disease losses at that time (Menzies et al. 1996). From 1996 to 2001 there appeared to be a lower incidence and severity of PD in Ireland (McLoughlin et al. 1998). However, in 2002 and 2003 there was an increase in both the severity and incidence of PD recorded in Ireland (McLoughlin et al. 2003).

An epidemiological survey undertaken in 2003 revealed that 13 of 21 sites ( $61 \%$ ) had experienced PD, with mortality reaching $40 \%$ in some cages (McLoughlin et al. 2003). There have also been reports from Scotland and Norway that PD has re-emerged as a significant problem in specific regions of both countries, resulting in mortalities of up to $25 \%$ of affected stock in 2003 and 2004.

As a result of the epidemiological survey carried out in Ireland in 2003, there was some indication that there was a significant difference in the PD-related mortality in different strains of farmed Atlantic salmon within individual farms (McLoughlin et al. 2003). Previous challenge tests with fish strains or families that were infected with specific pathogens have shown significant genetic variation in observed mortality due to genetic factors, indicating that improvement by selection is possible (Chevassus et al. 1990).

Reproducible experimental infections with SPDV have been demonstrated in Atlantic salmon, brown trout Salmo trutta L., and rainbow trout Oncorhynchus mykiss (Walbaum) (Boucher et al. 1995, Murphy et al. 1995, McLoughlin et al. 1996, Desvignes et al. 2002). While increased mortality has not been a significant finding in experimental SPDV challenge models, typical PD histopathological lesions in the pancreas, heart and skeletal muscle have been consistently described.

While these studies have sought to compare the outcomes of infection with the same virus between different fish species (Boucher et al. 1995, Weston et al. 2002), there are no published comparative evaluations of experimental infection in different strains of Atlantic salmon. There were indications from the field that salmon strains varied in their susceptibility to infection with SPDV, and the present work was therefore conducted as a preliminary study to investigate this field observation. Comparisons were made of the prevalence of lesions and their severity, of viraemia, and of serological responses and geometric mean titres
(GMT) in 3 commercial strains of Atlantic salmon experimentally infected with SPDV.

\section{MATERIALS AND METHODS}

Fish and sampling. Three distinct strains of Atlantic salmon, identified as Strains A, B and C, were selected for this study. Three strain-specific groups of $120 \mathrm{~g}$ smolts were allocated to 3 separate tanks and acclimatised for $7 \mathrm{wk}$ in disinfected (Redox $>800 \mathrm{mV}$ ), ambient temperature $\left(9 \pm 2^{\circ} \mathrm{C}\right)$ seawater. From these fish, a mixed control group (Group D) was established, comprising 25 fish from each strain group.

After this period of acclimatisation, the 3 separate strain groups (A, B and C) of 130 fish per group were anaesthetised and challenged by intraperitoneal injection with $0.1 \mathrm{ml}$ SPDV of titre $10^{6.5} \mathrm{TCID}_{50} \mathrm{ml}^{-1}$. Control fish (Group D) were injected intraperitoneally with $0.1 \mathrm{ml}$ phosphate buffered saline. Only healthy fish were admitted to the study. Fish were observed 4 times daily for 42 days post-infection (dpi).

Blood samples were taken from 10 random prechallenge and 10 fish per infected group at $7,10,14$, $21,28,35$ and 42 dpi. Five uninfected controls were similarly sampled after 10, 21, 35 and $42 \mathrm{~d}$. Tissue samples including pancreas, heart, skeletal muscle and brain were taken from 10 randomly selected pre-challenged fish and then from 10 fish per challenged group and 5 control fish at 10,21, 35 and 42 dpi.

At each sampling point, all sampled fish were humanely killed by a sharp blow to the head. Blood was taken from the caudal vein into plain blood tubes and serum was harvested after centrifugation or settling overnight at $+4^{\circ} \mathrm{C}$. The serum was stored at $-80^{\circ} \mathrm{C}$ until analysed. Tissues for histology (pancreas, heart, muscle including lateral line and brain) were fixed in $10 \%$ buffered formalin and processed by standard paraffin wax techniques and stained with haematoxylin and eosin (H \& E).

Tissues from the 4 groups were examined as a blind study by an experienced pathologist and the scoring system used to semi-quantify the distribution and severity of the tissue lesions is described in Table 1.

Virus neutralization testing and virus isolation. Virus neutralisation (VN) testing was performed as described previously (Graham et al. 2003). Briefly, sera were tested in duplicate at final dilutions of $1 / 20$ and 1/40 in a microtitre assay using monoclonal antibody 2D9 (Welsh et al. 2000) and an immunoperoxidase staining technique to reveal the presence or absence of virus. Sera with titres of $<1 / 20$ were considered negative. Where necessary, positive sera were retested in doubling dilutions from 1/20 to $1 / 1280$ to determine neutralizing antibody endpoints 
according to the method of Karber (1931). Serum samples (without added virus) were run in parallel with each VN test to identify viraemic serum. Immunostaining of these wells was used to identify the presence of virus in collected sera (Jewhurst et al. 2004).

Statistical analysis. Due to the limited ordinal nature of the recorded lesion scores (scored using a 0 to 4 scale), non-parametric analyses were used on this data. The Kruskal-Wallis 1-way ANOVA was used to test for significant differences in the mean ranks of lesion scores in each tissue among the 3 challenged strains at each time point (Siegel \& Castellan 1998). Significance levels were determined using exact methods to take account of the small sample numbers. Pairwise 2-tailed multiple comparison tests were used to identify significant differences in the mean ranks of lesion scores between pairs of challenged strains.

Tests of the proportions of fish with lesions in each challenged group were carried out using chi-square analysis and exact methods to compute significance. Thereafter, pair-wise comparisons of challenged strains were performed using the Pearson chi-square statistic to identify significant differences between challenged groups. Values were computed using exact methods to take account of the small numbers. Tests of the proportions of fish in each challenged group with detectable levels of virus or antibody at each time point and subsequent pair-wise analyses were performed in the same way. The mean geometric antibody titres of the challenged groups were compared at each time point using 1-way ANOVA to identify significant dif- ferences. Pair-wise 2-tailed comparison tests were carried out to identify significant differences in titres between challenged groups at each time point.

\section{RESULTS}

\section{Mortality data}

Mortality data were collected daily. Cumulative percentage mortality figures ranged from 3 to $12 \%$ (Fig. 1). Significant mortality is not a consistent feature of experimental pancreas disease (McLoughlin et al. 1996). Mortalities in all 4 groups were due to low grade skin lesions and osmotic stress and were not SPDV related; therefore, mortality data could not be used to evaluate any differences in PD susceptibility in this experiment.

\section{Histopathological lesions}

Lesions typical of experimental and naturally occurring SPDV infection were found to varying degrees in all 3 infected groups. No histological lesions were detected in any of the tissues from control fish examined. Histograms showing mean tissue lesion scores $( \pm \mathrm{SE})$ at $10,21,35$ and $42 \mathrm{~d}$ post-SPDV infection are presented in Figs. 2 to 5 (quantitative data). Proportions (qualitative data) of fish in each challenged group with lesions at each sample point are presented in Table 2. A summary of the statistical analyses of quali-

Table 1. Salmo salar. Semi-quantitative lesion score system used to compare lesion severity. (a) Pancreatic lesion classification. (b) Heart lesion classification. (c) Red and white skeletal muscle lesion classification

\begin{tabular}{ll}
\hline Score & Description \\
\hline (a) & Normal appearance \\
0 & Focal pancreatic acinar cell necrosis \\
1 & Significant multifocal necrosis/atrophy of pancreatic acinar tissue, plus some normal tissue remaining \\
2 & Total absence of pancreatic acinar tissue \\
3 & Recovery of pancreas \\
$\mathrm{R}$ & \\
$\mathbf{( b )}$ & Normal appearance \\
0 & Focal myocardial degeneration \pm inflammation $(<50$ fibres affected $)$ \\
1 & Multifocal myocardial degeneration \pm inflammation $(50-100$ fibres affected $)$ \\
2 & Severe diffuse myocardial degeneration \pm inflammation $(>100$ fibres affected $)$ \\
3 & Repair and/or regeneration \\
$\mathrm{R}$ & \\
(c) & Normal appearance \\
0 & Focal myocytic degeneration \pm inflammation \\
1 & Multifocal myocytic degeneration \pm inflammation \\
2 & Severe diffuse myocytic degeneration \pm inflammation \\
3 & Repair and/or regeneration \\
$\mathrm{R}$ &
\end{tabular}




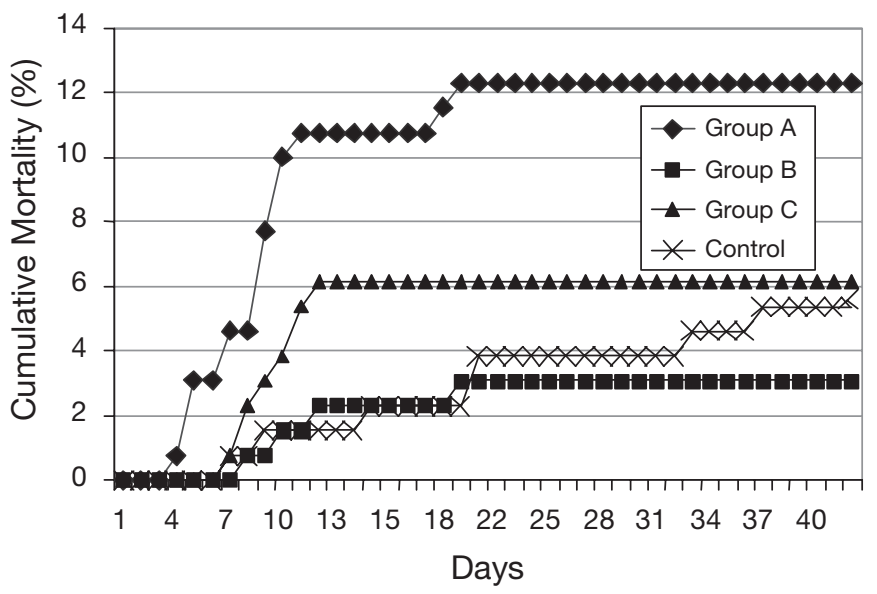

Fig. 1. Salmo salar. Mean cumulative percentage mortality data

tative and quantitative histological results for each challenge group is presented in Table 3.

\section{Pancreatic pathology}

At Day 10 pi, similar lesions were seen in all infected groups (Fig. 2). The majority of fish had significant pancreatic acinar cell atrophy or necrosis (score 2 or 3 ), with some retaining normal acinar tissue especially around the pancreatic ducts and islets of Langerhans. Acute pancreatic necrosis was observed in about $10 \%$ of fish, with the remainder of those affected having sub-acute lesions. One fish in Groups A and B and 5 fish in Group $\mathrm{C}$ had no pancreatic lesions. No pancreatic lesions were detected in the 5 control fish at this stage or thereafter.

At Day 21 pi, the majority of fish in all groups had moderate to severe pancreatic atrophy, with $30 \%$ of fish in Group B exhibiting total absence of pancreatic acinar tissue (Fig. 3). This level of pancreatic damage was not detected in any fish in Groups A or C at this

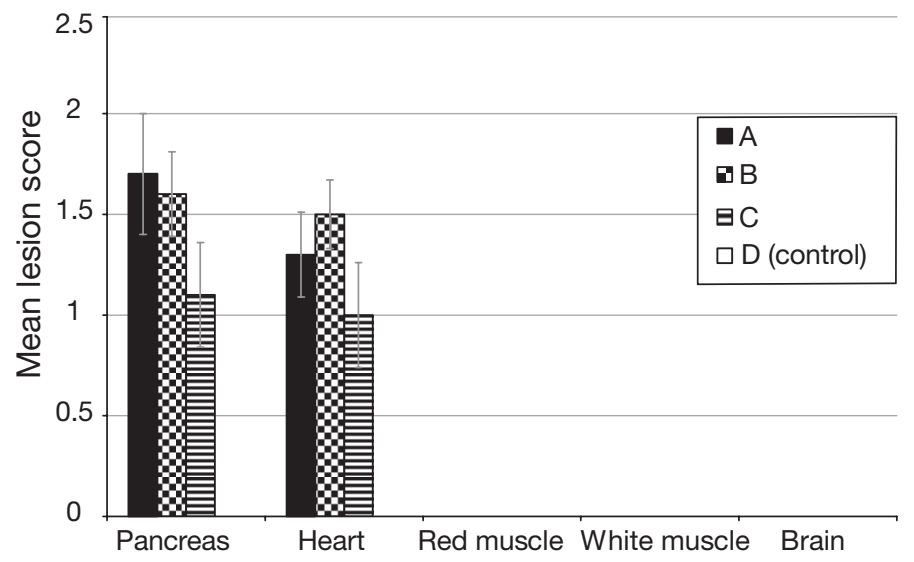

Fig. 2. Salmo salar. Mean tissue lesion scores \pm SE at $10 \mathrm{~d}$ post-SPDV infection stage post-infection. Three fish in Group A and 2 fish in Group C had no pancreatic lesions. At Days 35 and $42 \mathrm{pi}$, the pancreas had fully recovered in the majority of fish in all groups (Figs. 4 \& 5).

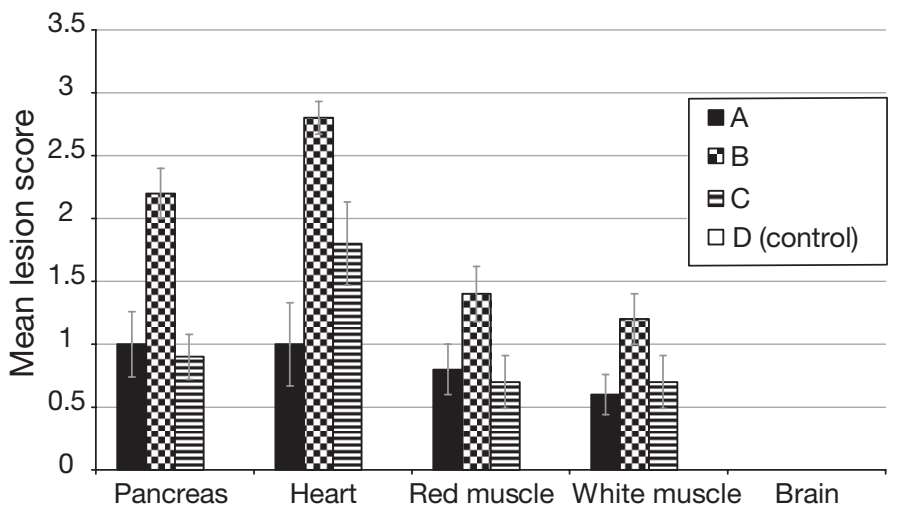

Fig. 3. Salmo salar. Mean tissue lesion scores \pm SE at 21 d postSPDV infection

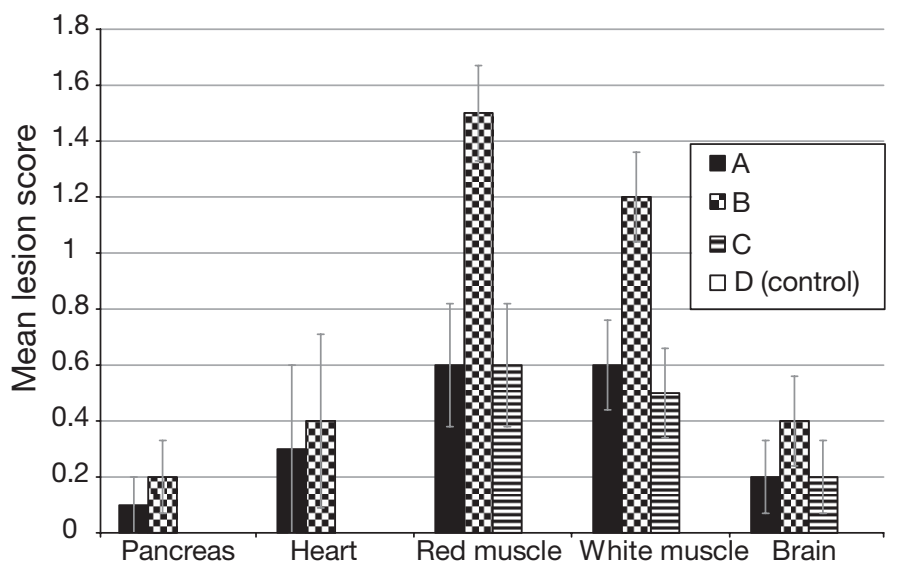

Fig. 4. Salmo salar. Mean tissue lesion scores $\pm \mathrm{SE}$ at $35 \mathrm{~d}$ postSPDV infection

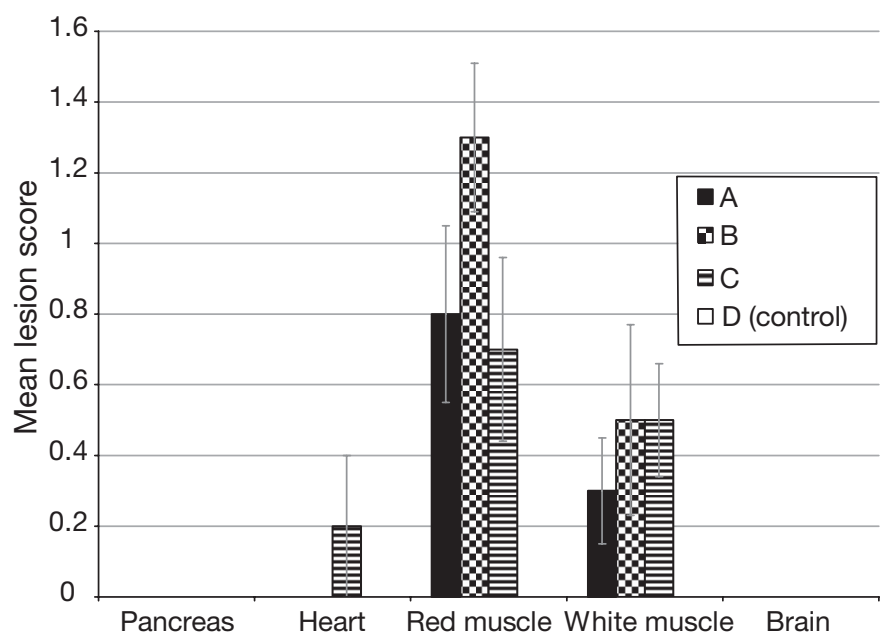

Fig. 5. Salmo salar. Mean tissue lesion scores \pm SE at 42 d postSPDV infection 
No significant differences were detected among challenged groups at each sample point in relation to the percentage of fish with pancreatic lesions (Table 2). However, comparison of mean pancreatic lesion scores at each sampling point revealed highly significant dif-

Table 2. Salmo salar. Proportion of fish in each challenged group with lesions at each sample point

\begin{tabular}{|lcccc|}
\hline \multirow{2}{*}{ Tissue } & dpi & \multicolumn{4}{c|}{ Challenge group } \\
& & A & B & C \\
\hline Pancreas & 10 & 0.9 & 0.9 & 0.5 \\
& 21 & 0.7 & 1 & 0.8 \\
& 35 & 0.1 & 0.2 & 0 \\
Heart & 42 & 0 & 0 & 0 \\
& 10 & 0.9 & 1 & 0.7 \\
& 21 & 0.5 & 1 & 0.8 \\
Red muscle & 35 & 0.1 & 0.2 & 0 \\
& 42 & 0 & 0 & 0.1 \\
& 10 & 0 & 0 & 0 \\
White muscle & 21 & 0.7 & 0.9 & 0.6 \\
& 35 & 0.5 & 1 & 0.5 \\
& 42 & 0.6 & 0.9 & 0.5 \\
& 10 & 0 & 0 & 0 \\
Brain & 21 & 0.6 & 0.9 & 0.6 \\
& 35 & 0.6 & 0.9 & 0.5 \\
& 42 & 0.3 & 0.3 & 0.5 \\
& 10 & 0 & 0 & 0 \\
& 21 & 0 & 0 & 0 \\
& 35 & 0.2 & 0.4 & 0.2 \\
& 42 & 0 & 0 & 0 \\
\hline
\end{tabular}

ferences $(\mathrm{p}<0.01)$ at Day 21 (Table 3). Further analysis indicated that the Day 21 mean score for Group B was significantly greater $(p<0.05)$ than that of both Groups A and C. Differences in pancreatic lesion scores at all other time points were not significant.

\section{Heart pathology}

At Day 10 pi, moderate acute focal to multifocal myocardiocytic degeneration characterised by shrunken eosinophilic cytoplasm, loss of striations and pyknotic nuclei was seen in both the spongy and compact layers of the ventricles (score 1 to 2 ) of the majority of fish (Fig. 2). Mild focal to diffuse epicarditis was also observed in some fish. One fish in Group A and 3 fish in Group C had no detectable heart lesions (Table 2).

By Day 21 pi, the hearts of all fish sampled from Group B had moderate to severe diffuse, multifocal myocardiocytic degeneration similar to that described at Day $10 \mathrm{pi}$, in addition to an early inflammatory response. This included infiltration of lymphocytes into the damaged tissue and hypertrophy of endocardial cells. Nuclear hypertrophy of myocardial nuclei at the junction of the compact and spongy ventricular muscle was also evident. In Group A, 50\% of fish had no detectable heart lesions and the remainder had moderate multifocal myocardial degeneration and inflammation. Six Group C fish had similar moderate heart

Table 3. Salmo salar. Summary of statistical analyses of qualitative and quantitative histological results for each challenge group. KW: Kruskal-Wallis 1-way ANOVA

\begin{tabular}{|c|c|c|c|c|c|c|c|c|c|}
\hline \multirow[t]{3}{*}{ Tissue } & \multirow[t]{3}{*}{ dpi } & \multicolumn{4}{|c|}{ Lesion prevalence (qualitative) } & \multicolumn{4}{|c|}{ Ranked lesion scores (quantitative) } \\
\hline & & \multirow[t]{2}{*}{$\chi^{2}$} & \multicolumn{3}{|c|}{ Multiple comparison } & \multirow[t]{2}{*}{ KW } & \multicolumn{3}{|c|}{ Multiple comparison } \\
\hline & & & $\mathrm{A}-\mathrm{B}$ & $\mathrm{A}-\mathrm{C}$ & $\mathrm{B}-\mathrm{C}$ & & $\mathrm{A}-\mathrm{B}$ & $\mathrm{A}-\mathrm{C}$ & $\mathrm{B}-\mathrm{C}$ \\
\hline \multirow[t]{4}{*}{ Pancreas } & 10 & - & - & - & - & - & - & - & - \\
\hline & 21 & - & - & - & - & $1 \%$ & $5 \%$ & - & $5 \%$ \\
\hline & 35 & - & - & - & - & - & - & - & - \\
\hline & 42 & - & - & - & - & - & - & - & - \\
\hline \multirow[t]{4}{*}{ Heart } & 10 & - & - & - & - & - & - & - & - \\
\hline & 21 & $5 \%$ & $5 \%$ & - & - & $1 \%$ & $5 \%$ & - & $10 \%$ \\
\hline & 35 & - & - & - & - & - & - & - & - \\
\hline & 42 & - & - & - & - & - & - & - & - \\
\hline \multirow[t]{4}{*}{ Red muscle } & 10 & - & - & - & - & - & - & - & - \\
\hline & 21 & - & - & - & - & $10 \%$ & - & - & - \\
\hline & 35 & $5 \%$ & $5 \%$ & - & $5 \%$ & $5 \%$ & $5 \%$ & - & $5 \%$ \\
\hline & 42 & - & - & - & - & - & - & - & - \\
\hline \multirow[t]{4}{*}{ White muscle } & 10 & - & - & - & - & - & - & - & - \\
\hline & 21 & - & - & - & - & $10 \%$ & - & - & - \\
\hline & 35 & - & - & - & - & $5 \%$ & - & - & $10 \%$ \\
\hline & 42 & - & - & - & - & - & - & - & - \\
\hline \multirow[t]{3}{*}{ Brain } & 10 & - & - & - & - & - & - & - & - \\
\hline & 21 & - & - & - & - & - & - & - & - \\
\hline & 35 & - & - & - & - & - & - & - & - \\
\hline
\end{tabular}


lesions, whereas 2 had more severe diffuse degeneration and inflammation. The remaining 2 fish had no detectable heart lesions (Fig. 3). At Days 35 and 42 pi, the heart had fully recovered in the majority of fish in all groups (Figs. 4 \& 5).

Significant differences in both the prevalence of lesions ( $p<0.05)$ and mean heart lesion score $(p<0.01)$ were detected among challenge groups at Day 21 only. Further testing indicated that the mean lesion scores for Group B were significantly higher than those of both group A $(p<0.05)$ and C $(p<0.1)$ (Table 3).

\section{Red and white skeletal muscle pathology}

At Day 10 pi, no abnormalities were found in the red or white muscle of any of the experimental groups (Fig. 2). By Day 21, mild acute focal myodegeneration was detected in both red and white skeletal muscle in all groups (Fig. 3). There were 3 fish in Group A, 1 fish in Group B and 4 fish in Group $C$ with no red muscle lesions, with 4 in Group A, 1 in Group B and 4 in Group C with no white muscle lesions.

At Day 35 pi, all fish in group B had red muscle lesions and 9 also had white muscle lesions. In contrast, only 5 fish from each of Groups A and C had red muscle lesions. Six fish from Group A and 5 from Group C had white muscle lesions (Fig. 4).

On Day 42 pi, the majority of fish in Groups A and B had mild to moderate myofibrillar degeneration with mild focal inflammation and fibrosis present in both red and white muscle, indicating an early repair process. In Group C, $50 \%$ of fish had no red or white muscle lesions and the remaining fish had very mild focal myofibrillar degeneration, with surrounding inflammation and occasionally focal fibrosis (Fig. 5).

Significant differences in both the prevalence of red muscle and mean red muscle lesion score $(\mathrm{p}<0.05)$ were detected among challenge groups at Day 35. Further testing indicated that mean lesion scores for Group B were significantly higher than those from both Groups A and C ( $<<0.05)$. Significant differences in mean white muscle lesion scores were also detected at Day 35 ( $\mathrm{p}<0.05)$; however, only differences between Groups B and C were significant, and then only at the $10 \%$ level (Table 3).

\section{Brain pathology}

Mild focal gliosis of the brainstem was noted in a small number of fish in all 3 experimental groups at Day 35 pi only (Fig. 4). The significance of these mild non-specific lesions is unclear. No brain lesions were seen in control fish.

\section{Virological and serological testing}

Viraemia was detected in 1 or more fish at 3,7 and 10 dpi in Groups B and C and at 3, 7, 10 and 14 dpi in Group A. Virus was detected in a total of 27 samples from Group B, 26 samples from Group A and 23 from Group C. The maximum percentage of viraemic sera detected in individual sample sets within each group was $90 \%$ (Fig. 6). There were no statistically significant differences $\left(p>0.05, \chi^{2}\right)$ between the numbers of viraemic fish detected in each challenged group at 3, 7, 10 and 14 dpi. All tests on Group D (controls) were negative for both virus and antibody.

Seropositive fish were first detected in all challenged groups on Day 17, with the majority of sera from each challenged group being seropositive from Day 21 onward. The serological response among the challenged groups was evaluated in relation to both the number of fish with detectable antibodies and mean geometric antibody titres (quantitative response, Fig. 7) at each sample point.

Qualitative results for Groups A and B were similar, even though the mean titre was higher in Group A from Day 28 pi onwards. Overall, both the qualitative and quantitative responses of Group $\mathrm{C}$ were less than those observed for Groups A and B. The among-group differences in qualitative responses at Days 28 and 35 pi were significant at the $10 \%$ level $(p=0.051$ and 0.089 respectively, $\chi^{2}$ ). The difference in the quantitative responses at Day 28 was highly significant $(p<$ 0.01, ANOVA), with pair-wise comparisons at this time indicating all groups to be significantly different $(\mathrm{p}<$

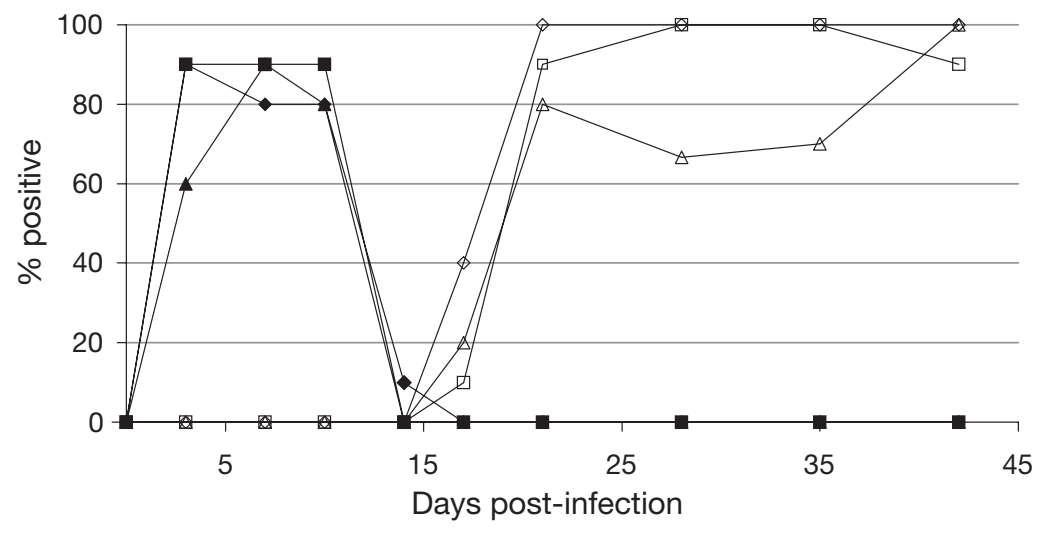

Fig. 6. Salmo salar. Comparison of levels of viraemia and seroprevalence between challenged Groups A $(\diamond, \diamond), B(\square, \square)$ and C $(\boldsymbol{\Delta}, \Delta)$. Closed symbols: viraemia results; open symbols: virus neutralisation (VN) antibody results 


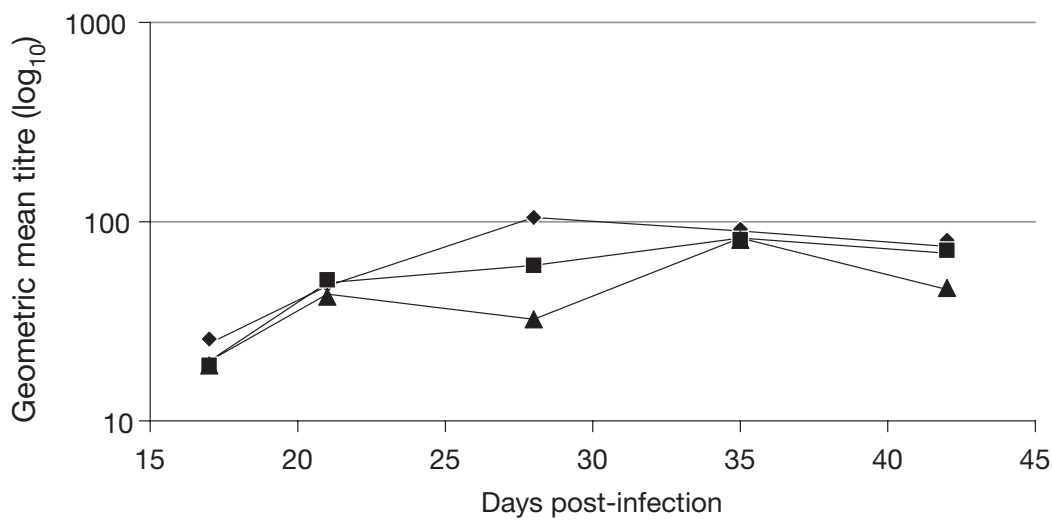

Fig. 7. Salmo salar. Quantitative serological results for challenged Groups A ( $\bullet)$, B ( $\square)$ and C ( $\mathbf{\Lambda})$ showing geometric mean titre of $\mathrm{VN}$ antibodies in seropositive fish at each sample point

0.05) from each other. All other differences in relation to serological testing were not significant.

\section{DISCUSSION}

Natural resistance is an integral part of fish health management and can be enhanced if disease resistant stocks of fish are selected for brood stock (Gjoen et al. 1997). Factors that influence the natural resistance of fish to disease are phagocytic activity of leucocytes and macrophages, tissue integrity, non-specific serum components such as interferon and complement, nutritional well-being, age, species, strains, families and environmental conditions.

There are 3 classical ways of measuring disease resistance: survival rate, challenge test and immunological or physiological parameters. Response to direct selection for increased survival in commercial environments has been low owing to inaccurate records in trials and practical difficulties in identifying the cause of death in individual fish (Fjalestad et al. 1993, Camp et al. 2000, Chin et al. 2004).

The main disadvantage of controlled challenge-testing is that it does not reproduce the environmental conditions in commercial farms, resulting in a reduction of the efficiency of challenge tests as a selection tool. However, challenge tests are eminently suitable for the type of preliminary investigation reported here, which was aimed at clarifying the field observation that there was a difference in susceptibility to SPDV infection in commercially farmed Atlantic salmon. Two of the strains used in this study are currently farmed commercially in Ireland.

Reproducible experimental infections with SPDV have been demonstrated in Atlantic salmon, brown trout and rainbow trout (Boucher et al. 1995, Murphy et al. 1995, McLoughlin et al. 1996, Desvignes et al. 2002). Typical PD histopathological lesions in the pancreas, heart and skeletal muscle have been consistently described. This has allowed us to semi-quantitatively describe differences in lesion prevalence and severity in the 3 fish strains under investigation. Significant mortality is not a consistent feature of experimental pancreas disease (McLoughlin et al. 1996). Mortalities that resulted from low grade skin lesions and osmotic stress were recorded in all 4 groups, and thus mortality data could not be used to evaluate any differences in disease resistance in this experiment.

The sequential pathology observed in this study was very similar to that previously described in Atlantic salmon smolts (McLoughlin et al. 1996, Desvignes et al. 2002).

Mild focal gliosis of the brainstem was noted in a small number of fish in all 3 experimental groups at Day 35 pi only. The significance of these mild nonspecific lesions is unclear; this is the first time brain lesions have been reported in experimental SPDV infections. Overall, the prevalence and severity of typical PD tissue lesions was greater in Group B, which confirmed the observations from field cases in Ireland where salmon strains A and B were commercially farmed (McLoughlin et al. 2003). These results confirm for the first time that there are strain differences in the severity and prevalence of SPDV-induced lesions in commercial farmed Atlantic salmon. While the lesions did not cause mortality in this challenge experiment, the lesion prevalence and severity revealed significant differences that under field conditions would probably affect survival rate.

Immunological and physiological parameters can also be measured to evaluate disease resistance in fish. The immune system of fish exhibits all the characteristic features of the immune system as known in mammals according to Ellis (1982).

In this study, viraemia was typically cleared within $2 \mathrm{wk}$ of intra-peritoneal infection, with antibody responses detectable from Day 17 onward. There was no overlap between viraemia and the presence of specific SPDV antibody (seroconversion) (Fig. 6). These findings are consistent with previous observations from longitudinal studies of both field and experimental SPDV and Sleeping Disease Virus (SDV) infections (McLoughlin et al. 1996, Desvignes et al. 2002, D. A. Graham unpubl. data). It has also been shown that passive immunisation with convalescent sera from infected salmon will prevent infection (Houghton \& Ellis 1996). An absence of overlap between viraemia and seroconversion indicates that a humoral response alone is not responsible for viral 
elimination from serum. In all groups, some fish exhibited no evidence of virus, antibody or histopathological lesions in any tissue at any or all sample points. This may suggest that these individual fish are refractory to both injection challenge and natural co-habitant infection, and they would be particularly useful to assess in future, more detailed investigations of the mechanism of resistance.

There were no significant differences seen among the challenged groups in relation to the percentage of viraemic fish at each time point. However, it has been reported for Venezuelan equine encephalitis virus (another alphavirus) that the level of viraemia produced by different enzootic and epizootic viral strains is a major determinant of their epidemic potential (Walton et al. 1973).

Future work will seek to compare the viral loads in sera among challenged groups at selected time points using a quantitative real time RT-PCR to investigate the possible correlation between this parameter and lesion scores. This will allow comparison with other alphaviral models and perhaps indicate if viral loading and shedding capacity of the different strains of fish is important in the epidemiology and pathogenesis of PD in these fish strains. It is not clear if disease resistance to SPDV is a heritable trait, and further field and experimental challenges comparing fish strains and families will be required in order to investigate this observation.

Acknowledgements. This work was part-funded by Framework 5 EU grant QLK2-CT-2001-00970 and by Marine Institute (Galway) and Marine Harvest Ltd.

\section{LITERATURE CITED}

Boucher P, Raynard RS, Houghton G, Baudin Laurencin F (1995) Comparative experimental transmission of pancreas disease in Atlantic salmon, rainbow trout and brown trout. Dis Aquat Org 22:19-24

Camp KL, Wolters WR, Rice CD (2000) Survivability and immune responses after challenge with Edwardsiella ictaluri in susceptible and resistant families of channel catfish, Ictalurus punctatus. Fish Shellfish Immunol 10: 475-487

Chevassus B, Dorson M (1990) Genetics of resistance to disease in fishes. Aquaculture 85:83-107

Chin A, Glebe BD, Woo PTK (2004) Humoral response and susceptibility of five full-sib families of Atlantic salmon, Salmo salar L., to the haemoflagellate, Cryptobia salmositica. J Fish Dis 27:471-481

Desvignes L, Quentel C, Lamour F, Leven A (2002) Pathogenesis and immune response in Atlantic salmon (Salmo salar L.) parr experimentally infected with salmon pancreas disease virus (SPDV). Fish Shellfish Immunol 12:77-95

Ellis AE (1982) Differences between the immune mechanisms of fish and higher vertebrates. In: Roberts RJ (ed) Microbial diseases of fish. Academic Press, London, p 1-29
Ferguson HW, Roberts RJ, Richards RH, Collins RO, Rice DA (1986a) Severe degenerative cardiomyopathy associated with pancreas disease in Atlantic salmon, Salmo salar L. J Fish Dis 20:95-98

Ferguson HW, Rice DA, Lynas JK (1986b) Clinical pathology of myodegeneration (pancreas disease) in Atlantic salmon (Salmo salar). Vet Rec 119:297-299

Fjalestad KT, Gjedrem T, Gjerde B (1993) Genetic improvement of disease resistance in fish: an overview. Aquaculture 111:65-74

Gjoen HM, Refstie T, Ulla O, Gjerde B (1997) Genetic correlations between survival of Atlantic salmon in challenge and field tests. Aquaculture 158:277-288

Graham D, Jewhurst V, Rowley H, McLoughlin M, Todd D (2003) A rapid immunoperoxidase-based virus neutralization assay for salmonid alphavirus used for a serological survey in Northern Ireland. J Fish Dis 26:407-413

Houghton G, Ellis AE (1996) Pancreas disease in Atlantic salmon: serum neutralisation and passive immunisation. Fish Shellfish Immunol 6:465-472

Jewhurst VA, Todd D, Rowley HM, Walker IW, Weston JH, McLoughlin MF, Graham DA (2004) Detection and antigenic characterization of salmonid alphavirus isolates from sera obtained from farmed Atlantic salmon, Salmo salar L., and farmed rainbow trout, Oncorhynchus mykiss (Walbaum). J Fish Dis 27:143-149

Karber G (1931) Beitrag zur kollekiven Behandlung pharmalologischer Reihenversuche. Arch Exp Pathol Pharmacol 162:480-483

Kent ML, Elston RA (1987) Pancreas disease in pen-reared Atlantic salmon in North America. Bull Eur Assoc Fish Pathol 7:29-31

McLoughlin MF, Nelson RT, Rowley HM, Cox DI, Grant AN (1996) Experimental pancreas disease in Atlantic salmon Salmo salar post-smolts induced by salmon pancreas disease virus (SPDV). Dis Aquat Org 26:117-124

McLoughlin MF, Rowley HM, Doherty CE (1998) A serological survey of salmon pancreas disease virus (SPDV) antibodies in farmed Atlantic salmon Salmo salar L. J Fish Dis 21:305-307

McLoughlin MF, Peeler E, Foyle KL, Rodger HD, O'Ceallachain D, Geoghegan F (2003) An epidemiological investigation of the re-emergence of pancreas disease in Irish farmed Atlantic salmon (Salmo salar L.) in 2002. Marine Institute, Galway

McVicar AH (1987) Pancreas disease of farmed Atlantic salmon, Salmo salar, in Scotland: epidemiology and early pathology. Aquaculture 67:71-78

McVicar AH (1990) Infection as a primary cause of pancreas disease in farmed Atlantic salmon. Bull Eur Assoc Fish Pathol 10:84-87

Menzies FD, Wheatley SB, Goodall EA, McLoughlin MF (1996) Development of a computerised information retrieval system for Atlantic salmon, Salmo salar L., production. Aquac Res 27:183-190

Munro ALS, Ellis AE, McVicar AH, McLay HA, Needham EA (1984) An exocrine pancreas disease of farmed Atlantic salmon in Scotland. Helgol Meeresunters 37: 571-586

Murphy TM, Rodger HD, Drinan EM, Gannon F, Kruse P, Korting W (1992) The sequential pathology of pancreas disease in Atlantic salmon farms in Ireland. J Fish Dis 15: 401-408

Murphy TM, Drinan EM, Gannon F (1995) Studies with an experimental model for pancreas disease of Atlantic salmon Salmo Salar L. Aquac Res 26:861-874

Nelson RT, McLoughlin MF, Rowley HM, Platten MA, 
McCormick JI (1995) Isolation of a toga-like virus from farmed Atlantic salmon Salmo salar with pancreas disease. Dis Aquat Org 22:25-32

Poppe T, Rimstad E, Hyllseth B (1989) Pancreas disease of Atlantic salmon (Salmo Salar, L.) post-smolts infected with infectious pancreatic necrosis virus (IPNV). Bull Eur Assoc Fish Pathol 9:83-85

Rodger HD, Murphy TM, Drinan EM, Rice DA (1991) Acute skeletal myopathy in farmed Atlantic salmon Salmo salar. Dis Aquat Org 12:17-23

Rodger HD, Turnbull T, Richards RH (1994) Myopathy and pancreas disease in salmon: a retrospective study in Scotland. Vet Rec 135:234-235

Siegel S, Castellan Jr NJ (1998) Nonparametric statistics for the behavioral sciences. McGraw-Hill, New York

Walton TE, Alvarez O Jr, Buckerwalter RM, Johnson KM

Editorial responsibility: Jo-Ann Leong,

Kaneohe, Hawaii, USA
(1973) Experimental infection of horses with enzootic and epizootic strains of Venezuelan equine encephalomyelitis virus. J Infect Dis 128:271-282

Welsh M, Weston JH, Borghmans BJ, Mackie D, Rowley $\mathrm{H}_{\text {, }}$ Nelson R, McLoughlin M, Todd D (2000) Biochemical characterisation of salmon pancreas disease virus. J Gen Virol 81:813-820

Weston JH, Welsh MD, McLoughlin MF, Todd D (1999) Salmon pancreas disease virus, an alphavirus infecting farmed Atlantic salmon, Salmo salar L. Virology 256: 188-195

Weston J, Villoing S, Brémont M, Castric J and 7 others (2002) Comparison of two aquatic alphavirus, salmon pancreas disease virus and sleeping disease virus, by using genome sequence analysis, monoclonal reactivity, and crossinfection. J Virol 76:6155-6163

Submitted: August 11, 2005; Accepted: March 20, 2006

Proofs received from author(s): September 28, 2006 